ARTICLE

DOI: $10.1038 / s 41467-017-00382-1$

OPEN

\title{
Energetics of Baird aromaticity supported by inversion of photoexcited chiral [4n]annulene derivatives
}

Michihisa Ueda', Kjell Jorner (10 2, Young Mo Sung ${ }^{3}$, Tadashi Mori (i] ${ }^{4}$, Qi Xiao', Dongho Kim ${ }^{3}$, Henrik Ottosson ${ }^{2}$, Takuzo Aida (1) ${ }^{1,5} \&$ Yoshimitsu Itoh (D) ${ }^{1}$

For the concept of aromaticity, energetic quantification is crucial. However, this has been elusive for excited-state (Baird) aromaticity. Here we report our serendipitous discovery of two nonplanar thiophene-fused chiral $[4 n]$ annulenes ${ }^{\text {Th4 }}{ }^{\mathbf{C O}} \mathbf{T}_{\text {saddle }}$ and ${ }^{\mathbf{T}}{ }^{\mathbf{6}} \mathbf{C D H}_{\mathbf{s c r e w}}$, which by computational analysis turned out to be a pair of molecules suitable for energetic quantification of Baird aromaticity. Their enantiomers were separable chromatographically but racemized thermally, enabling investigation of the ring inversion kinetics. In contrast to ${ }^{\mathbf{T h}} \mathbf{C D H H}_{\mathbf{S c r e w}}$, which inverts through a nonplanar transition state, the inversion of ${ }^{\text {Th4 }}$ COT $_{\text {Saddle, }}$ progressing through a planar transition state, was remarkably accelerated upon photoexcitation. As predicted by Baird's theory, the planar conformation of ${ }^{\text {Th4 }}{ }^{\mathbf{C O}} \mathbf{T}_{\text {Saddle }}$ is stabilized in the photoexcited state, thereby enabling lower activation enthalpy than that in the ground state. The lowering of the activation enthalpy, i.e., the energetic impact of excitedstate aromaticity, was quantified experimentally to be as high as $21-22 \mathrm{kcal} \mathrm{mol}^{-1}$.

\footnotetext{
${ }^{1}$ Department of Chemistry and Biotechnology, School of Engineering, The University of Tokyo, 7-3-1 Hongo, Bunkyo-ku, Tokyo 113-8656, Japan. ${ }^{2}$ Department of Chemistry - Angström Laboratory, Uppsala University, Box 523, Uppsala 751 20, Sweden. ${ }^{3}$ Spectroscopy Laboratory for Functional $\pi$-Electronic Systems and Department of Chemistry, Yonsei University, Seoul 120-749, Korea. ${ }^{4}$ Department of Applied Chemistry, Graduate School of Engineering, Osaka University, 2-1 Yamada-oka, Suita, Osaka 565-0871, Japan. ${ }^{5}$ RIKEN Center for Emergent Matter Science, 2-1 Hirosawa, Wako, Saitama 351-0198, Japan. Correspondence and requests for materials should be addressed to D.K. (email: dongho@yonsei.ac.kr) or to H.O. (email: henrik.ottosson@kemi.uu.se) or to T.A. (email: aida@macro.t.u-tokyo.ac.jp) or to Y.I. (email: itoh@macro.t.u-tokyo.ac.jp)
} 
A nnulenes are monocyclic hydrocarbons comprising alternating single and double bonds, whose preferred conformations in the electronic ground $\left(\mathrm{S}_{0}\right)$ state are determined by the number of their $\pi$-electrons ${ }^{1}$. Annulenes with $4 n+2 \pi$-electrons are categorized as Hückel aromatic compounds that prefer to adopt a bond-length equalized planar conformation because the electronic conjugation enabled by planarization leads to energetic stabilization ${ }^{2,}{ }^{3}$. In contrast, annulenes with $4 n \pi$-electrons are categorized as Hückel antiaromatic compounds that tend to adopt a bond-length alternate nonplanar conformation because of their unfavorable electronic conjugation and/or increased ring strain ${ }^{4-8}$. In 1972, Baird theoretically deduced $^{9}$ that $[4 n]$ annulenes in the triplet excited $\left(\mathrm{T}_{1}\right)$ state, just like $[4 n+2]$ annulenes in the $S_{0}$ state, prefer to adopt a planar conformation because the resulting electronic conjugation leads to energetic stabilization ${ }^{10,11}$. Later, Baird's theory was shown computationally to be also applicable to the singlet excited $\left(\mathrm{S}_{1}\right)$ state $^{12-14}$. Indeed, a series of photochemical and photophysical phenomena that cannot be explained by Hückel's rule have been reasonably explained by Baird's rule ${ }^{15}, 16$. For example, Wan et al. utilized the concept of excited-state aromaticity to explain why certain $S_{\mathrm{N}}$ 1-type substitution reactions involving cyclic intermediates with $4 n \pi$-electrons are facilitated by photoirradiation ${ }^{17-20}$. Ottosson, Kilså, and coworkers ${ }^{21,22}$ showed that
Baird's rule can account for how the excitation energy of fulvene changes with its substituents. Indeed, Ottosson, and coworkers ${ }^{23}$ postulated that Baird's theory is a useful back-of-an-envelope tool for the design and exploration of novel photofunctional materials, and also showed that it can be used to develop new photoreactions $^{24,25}$. As a seminal achievement to elucidate Baird's rule, Kim, Osuka, and coworkers recently provided spectroscopic evidence of Baird aromaticity based on the transient absorption spectral profiles of a particular type of expanded porphyrin derivative ${ }^{26-28}$. Equally important for experimentally substantiating Baird's rule is to energetically quantify the concept of excited-state aromaticity ${ }^{6}$. However, this essential issue has not been addressed because annulene derivatives that fulfill certain prerequisites are currently unavailable.

In the course of our study on the synthesis of thiophene oligomers using a modified Ullmann coupling reaction, we noticed two different chiral $[4 n]$ annulene derivatives as by-products: ${ }^{\text {Th4 }}{ }^{\mathrm{COT}}{ }_{\text {Saddle }}$ and ${ }^{\text {Th6 }}{ }^{6 D H_{\text {Screw }}}$. Single-crystal Xray crystallographic analysis revealed that these by-products are nonplanar and conformationally chiral. We succeeded in their optical resolution using high-performance liquid chromatography on a chiral stationary phase (chiral HPLC). Circular dichroism (CD) spectroscopy in methylcyclohexane showed that the enantiomers of ${ }^{\mathrm{Th} 4}{ }^{\mathrm{COT}}$ Saddle and ${ }^{\mathrm{Th} 6} \mathrm{CDH}_{\text {Screw }}$ are racemized a
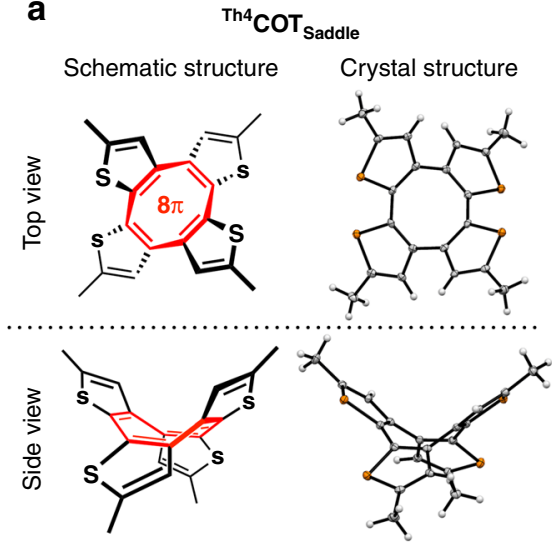

C

Transition state: plana
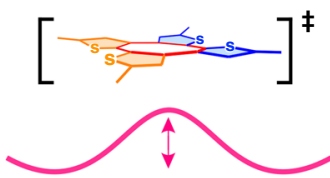

$\mathrm{S}_{1}$ and $\mathrm{T}_{1}$ states

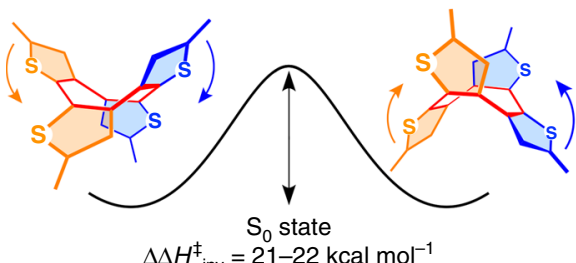

$\Delta \Delta H^{\ddagger}{ }_{\text {inv }}=21-22 \mathrm{kcal} \mathrm{mol}^{-1}$

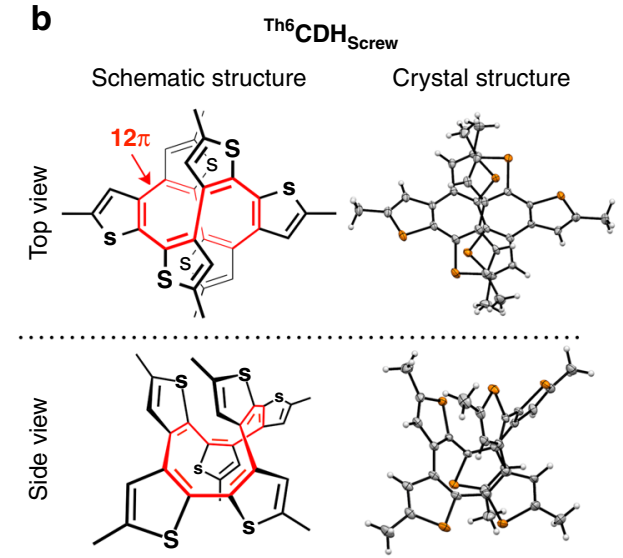

d

Transition state: nonplanar

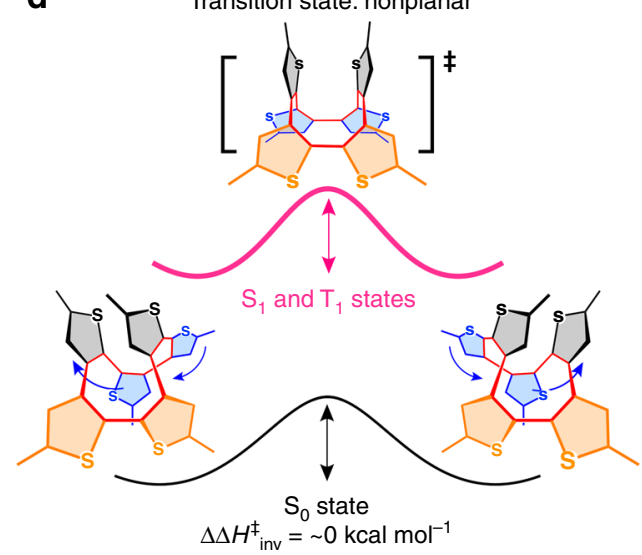

Fig. 1 [4n]Annulene derivatives with and without Baird aromaticity upon photoexcitation. a, b, Molecular structures and ORTEP drawings (50\% ellipsoid probability) of ${ }^{\text {Th4 }}{ }^{\mathbf{C O O T}} \mathbf{S a d d l e}_{\text {Sa) and }}{ }^{\mathbf{T}}{ }^{\mathbf{6}} \mathbf{C D H}_{\mathbf{S c r e w}}(\mathbf{b})$, which have $8 \pi$-electron and $12 \pi$-electron annulene cores (red colored), respectively. c, $\mathbf{d}$, Schematic illustrations of the energy barriers for the ring inversion events of ${ }^{\mathbf{T h}}{ }^{\mathbf{C}} \mathbf{O} \mathbf{T}_{\text {Saddle }}(\mathbf{c})$ and ${ }^{\mathbf{T h}} \mathbf{6} \mathbf{C D H}_{\text {Screw }}(\mathbf{d})$, where colored arrows represent the movement directions of the thiophene rings of the same color. ${ }^{\mathbf{T h} 4}{ }^{\mathbf{C O}} \mathbf{T}_{\text {Saddle }}$ and ${ }^{\mathbf{T}}{ }^{\mathbf{C}} \mathbf{C D H}_{\mathbf{s c r e w}}$ invert through planar and nonplanar transition states, respectively, as shown in the square brackets. Black and pink-colored solid curves represent energy barriers in the ground and photoexcited states, respectively. Upon photoexcitation, the activation enthalpy for the ring inversion $\left(\Delta H^{t}\right.$ inv $)$ of ${ }^{\mathbf{T h}}{ }^{\mathbf{C}} \mathbf{O T}_{\text {Saddle }}$ is lowered by $21-22 \mathrm{kcal}_{\mathrm{mol}}{ }^{-1}$, but that of ${ }^{\text {Th6 }} \mathbf{C D H}_{\mathbf{S c r e w}}$ remains unchanged 

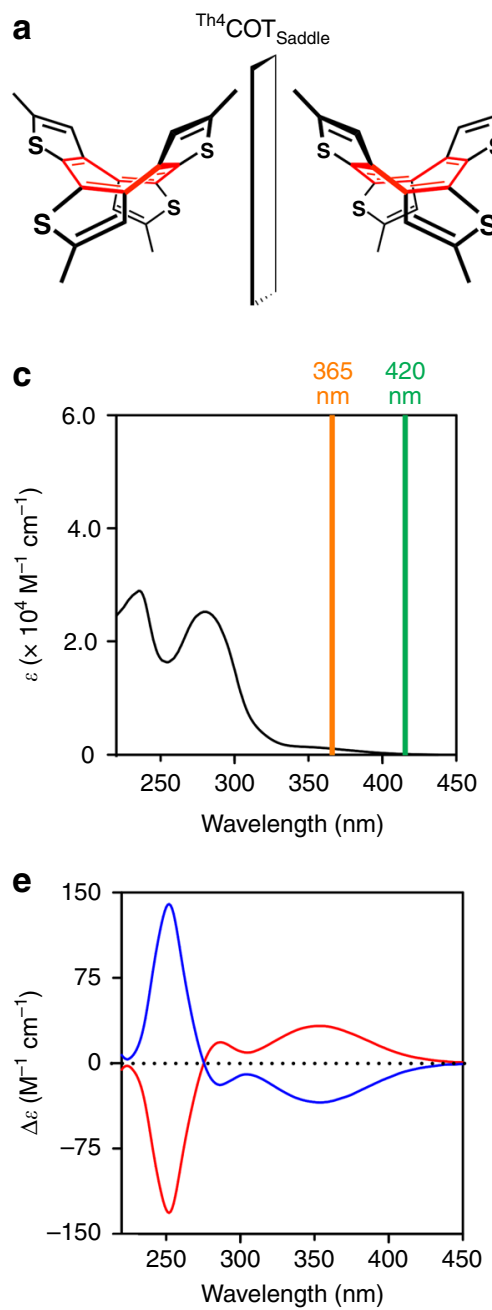

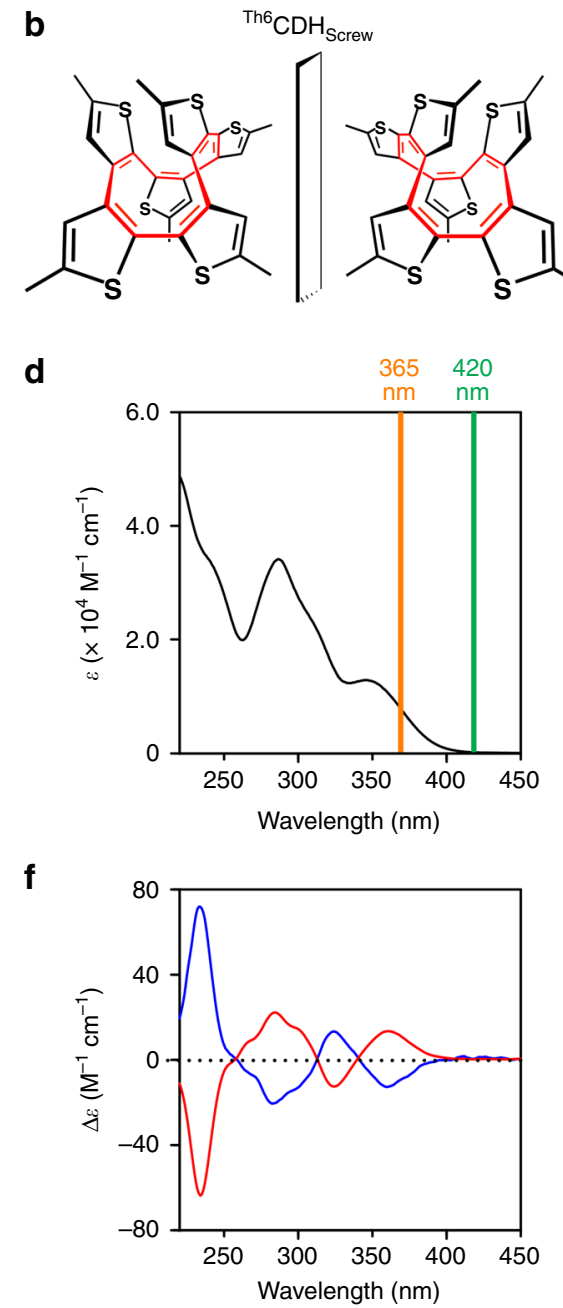

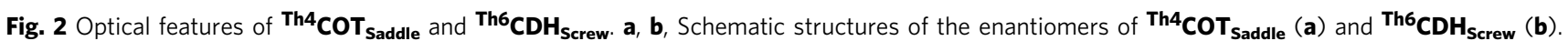
c, d, Electronic absorption spectra of ${ }^{\mathbf{T h 4}}{ }^{\mathbf{C O}} \mathbf{T}_{\text {Saddle }}(\mathbf{c})$ and ${ }^{\mathbf{T}}{ }^{\mathbf{6}} \mathbf{C D H}_{\text {screw }}$ (d) in methylcyclohexane at $25^{\circ} \mathrm{C}$. Orange- and green-colored vertical lines correspond to the wavelengths of $\lambda=365$ and $420 \mathrm{~nm}$, which were utilized for direct and sensitized photoexcitation of the molecules, respectively. e, $\mathbf{f}$, Circular dichroism (CD) spectra of ${ }^{\mathbf{T h}}{ }^{\mathbf{4}} \mathbf{C O T}_{\text {Saddle }}(\mathbf{e})$ and ${ }^{\mathbf{T h}}{ }^{\mathbf{C}} \mathbf{C D H}_{\mathbf{S c r e w}}$ (f) in methylcyclohexane at 25 and $-20{ }^{\circ} \mathrm{C}$, respectively. Blue- and red-colored traces represent the spectra of compounds obtained as the first and second fractions of the chiral HPLC, respectively

through ring inversion under appropriate conditions. Density functional theory (DFT) calculations indicated that ${ }^{\text {Th4 }}{ }^{\text {COT }}$ Saddle adopts a planar conformation, whereas ${ }^{\mathrm{Th}}{ }^{6} \mathrm{CDH}_{\text {Screw }}$ adopts a nonplanar conformation, in the transition state of their ring inversion processes. Of particular importance, we found that the racemization of ${ }^{\mathrm{Th}}{ }^{4} \mathrm{COT}_{\text {Saddle }}$ is remarkably accelerated by its photoexcitation, whereas that of ${ }^{\text {Th6 }}{ }^{\mathbf{C D H}} \mathbf{H}_{\text {Screw }}$ is unaffected by photoexcitation. We wondered whether these contrasting results are related to a prime issue of excited-state aromaticity, i.e., Baird aromaticity. In fact, quantum chemical computational analysis revealed that ${ }^{\text {Th4 }}{ }^{\mathrm{COT}} \mathrm{C}_{\text {Saddle }}$ and ${ }^{\mathrm{Th}}{ }^{\mathrm{C}} \mathrm{CDH}_{\text {Screw }}$ are a pair of molecules suitable for energetic quantification of Baird aromaticity. Previous studies demonstrated experimentally that cyclooctatetraene (COT), oxepin, and thiepin analogs in the photoexcited state adopt planar conformations ${ }^{29,} 30$. However, they are planarized only in a barrierless manner, precluding energetic quantification of photoexcited planar [4n]annulenes. On the other hand, ${ }^{\text {Th4 }}{ }^{\text {COT }}$ Saddle $_{\text {in the present study provides }}$ a sterically congested ring inversion process with a positive activation enthalpy. Because the transition state of the ring inversion of ${ }^{\text {Th4 }}{ }^{C O T_{\text {Saddle }}}$ involves its planarized core, the kinetic studies both in the $S_{0}$ state and photoexcited $\left(S_{1} / T_{1}\right)$ state surely enable us to support Baird's rule from an energetic viewpoint.

\section{Results}

Synthesis and optical resolution of ${ }^{\mathrm{Th}}{ }^{\mathrm{COT}}$ Saddle and ${ }^{\text {Th6 }} \mathrm{CDH}_{\text {Screw. }}$ A $\beta$-linked thiophene dimer (Th2) was subjected to a modified Ullmann coupling reaction, and the crude reaction mixture was passed through a silica gel short column and submitted to size exclusion chromatography on a polystyrene gel column for the isolation of ${ }^{\text {Th4 } 4} \mathrm{COT}_{\text {Saddle }}$ and ${ }^{\mathrm{T}}{ }^{6} \mathrm{CDH}_{\text {Screw }}$ (Supplementary Methods). $\quad{ }^{\mathrm{T} 4}{ }^{\mathrm{COOT}} \mathrm{COddle}_{\text {Sarries a }}$ COT ([8]annulene)

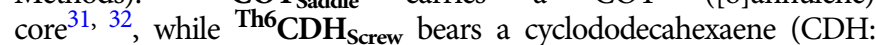
[12] annulene) core $^{33}$. Through vapor diffusion, all these annulenes afforded single crystals suitable for X-ray crystallography (Fig. 1a, b). The crystal structure of ${ }^{\mathrm{Th} 4}{ }^{\mathbf{C O O T}}$ Saddle adopts a highly nonplanar conformation in its annulene core with a bond-length alternation. A similar structural feature was observed for the crystal of ${ }^{\text {Th6 }} \mathbf{C D H}_{\text {Screw }}$. Chiral HPLC (Supplementary Methods) was used to separate these chiral compounds into the corresponding enantiomers (Fig. 2e, f). Their enantiomers were thermally racemizable, which encouraged us to investigate the ring inversion kinetics. The enantiomers of ${ }^{\mathrm{Th} 4}{ }^{4} \mathrm{COT}_{\text {Saddle, when heated above }} 40^{\circ} \mathrm{C}$ in methylcyclohexane, underwent racemization (Fig. 3a), while those of ${ }^{\text {Th6 }}{ }^{\mathrm{CDH}_{\text {Screw }}}$ were much more prone to racemization; the enantiomers of ${ }^{{ }^{16}}{ }^{6} \mathrm{CDH}_{\text {Screw }}$ were racemized unless the compound was cooled below $-40{ }^{\circ} \mathrm{C}$ (Fig. 3b). 

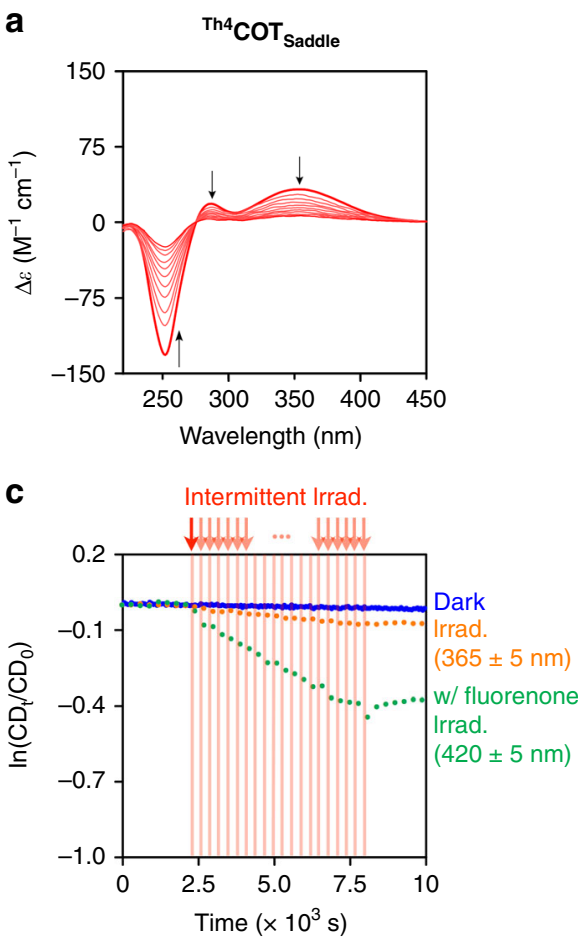

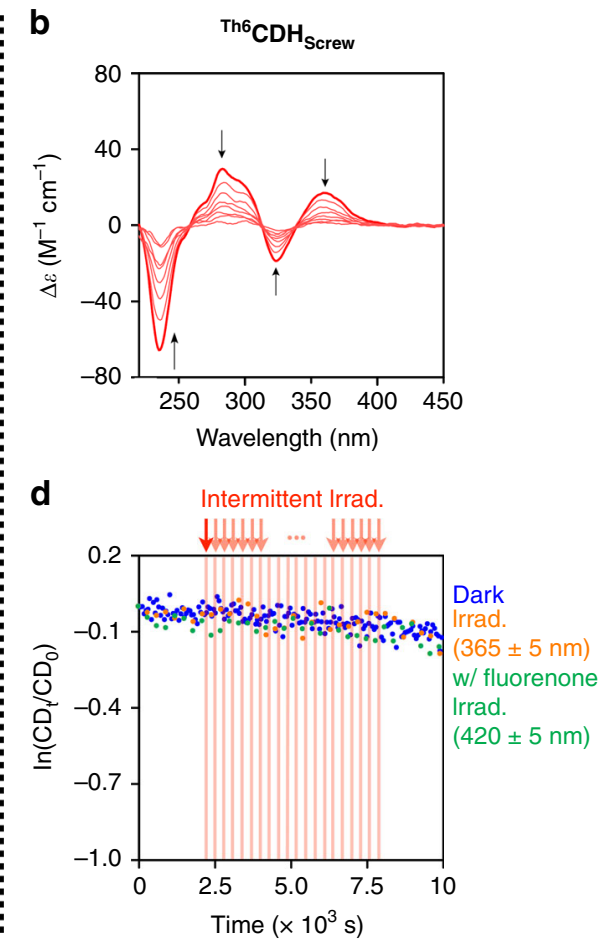

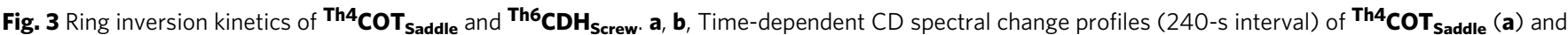
${ }^{\text {Th6 }} \mathbf{C D H}_{\text {Screw }}$ (b) in methylcyclohexane at 60 and $0{ }^{\circ} \mathrm{C}$, respectively. Black arrows in $\mathbf{a}$ and $\mathbf{b}$ represent the directions of the $\mathrm{CD}$ spectral change with time. c, d, Decay profiles of the CD intensities at $260 \mathrm{~nm}\left(\mathbf{c},{ }^{\mathbf{T h}}{ }^{\mathbf{C}} \mathbf{O} \mathbf{T}_{\text {Saddle }}\right)$ and $280 \mathrm{~nm}\left(\mathbf{d},{ }^{\mathbf{T h} 6} \mathbf{C D H}_{\text {screw }}\right)$ in deaerated methylcyclohexane at 20 and $-20{ }^{\circ} \mathrm{C}$, respectively. Blue-colored dots represent decay profiles without photoirradiation. Orange-colored dots represent decay profiles with photoirradiation ( $\lambda=365$ $\pm 5 \mathrm{~nm})$. Green-colored dots represent decay profiles with photoirradiation $(\lambda=420 \pm 5 \mathrm{~nm})$ in the presence of fluorenone $\left(0.34\right.$ equiv. for Th4 $\mathbf{C O} \mathbf{T}_{\text {Saddle }}$ and 0.23 equiv. for ${ }^{\mathbf{T h}}{ }^{\mathbf{C D H}} \mathbf{H}_{\mathbf{s c r e w}}$ ). Photoirradiation ( $250 \mathrm{~s}$, red vertical lines) and CD spectroscopy (50 s, white area between red vertical lines) were conducted alternately for $6000 \mathrm{~s}$

Ring inversion in the electronic ground and excited states. The inversion kinetics of ${ }^{\mathrm{Th}}{ }^{\mathrm{COT}} \mathbf{T}_{\text {Saddle }}$ and ${ }^{\mathrm{Th}}{ }^{6} \mathrm{CDH}_{\text {Screw }}$ were studied in deaerated methylcyclohexane. Neither compound decomposed under photoexcitation (Supplementary Figs. 8 and 9). For the selective generation of the $S_{1}$ state, ${ }^{\text {Th4 }}{ }^{\mathbf{C O T}}$ Saddle and ${ }^{\mathrm{Th}}{ }^{\mathbf{6}} \mathrm{CDH}_{\text {Screw }}$ were photoexcited at their longest wavelength absorption bands $(\lambda=365 \pm 5 \mathrm{~nm}$, Fig. $2 \mathrm{c}, \mathrm{d})$. At $20^{\circ} \mathrm{C}$ in the

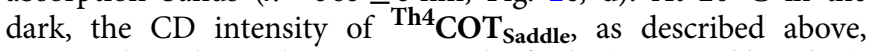
remained unchanged over a period of $3 \mathrm{~h}$ (Fig. 3c, blue dots). However, when the solution was irradiated under otherwise identical conditions, the $\mathrm{CD}$ intensity gradually decreased (half-life $\left(t_{1 / 2}\right)=12 \mathrm{~h}$ ) (Fig. $3 \mathrm{c}$, orange dots). When the photoirradiation was stopped, the CD intensity no longer decreased. Transient absorption spectroscopy (TAS) of ${ }^{\text {Th4 }}$ COT $_{\text {Saddle }}$ upon photoexcitation at $\lambda=355 \mathrm{~nm}$ enabled us to detect the $S_{1}$ state dynamics, which decayed exponentially with a lifetime of $5.5 \mathrm{ps}$ (Supplementary Fig. 16). No other excited species, including the $\mathrm{T}_{1}$ state, were detected. Hence, we conclude that the $\mathrm{S}_{1}$ state of ${ }^{\mathrm{Th}}{ }^{4} \mathrm{COT}_{\text {Saddle }}$ can facilitate its ring inversion.

Because Baird aromaticity has typically been discussed in the $\mathrm{T}_{1}$ state $^{9,11,34-36}$, it is important to confirm whether the ring inversion of ${ }^{\text {Th4 }}{ }^{\mathbf{C O T}} \mathbf{T}_{\text {Saddle }}$ is facilitated in its triplet excited state. Therefore, we selectively generated the $\mathrm{T}_{1}$ state of ${ }^{\mathrm{Th} 4}{ }^{\mathbf{C O O T}} \mathbf{T}_{\text {Saddle }}$ by photoexcitation of fluorenone ( 0.34 equiv., $E_{\mathrm{T}}=50.9 \mathrm{kcal}$ $\mathrm{mol}^{-1}, \varphi_{\mathrm{T}}=1.00^{37}$ ) at $\lambda=420 \pm 5 \mathrm{~nm}$ as a triplet photosensitizer and investigated the ring inversion process of ${ }^{\mathrm{Th} 4} \mathrm{COT}_{\text {Saddle }}$ at $20^{\circ} \mathrm{C}$. Although ${ }^{\mathrm{Th} 4} \mathrm{COT}_{\text {Saddle }}$ does not absorb light in this wavelength region $\left(\varepsilon=\sim 60 \mathrm{~cm}^{-1} \mathrm{M}^{-1}\right.$; Fig. $\left.2 \mathrm{c}\right)$, the ring inversion of ${ }^{\mathrm{Th} 4} \mathrm{COT}_{\text {Saddle }}$ was remarkably facilitated $\left(t_{1 / 2}=2.1 \mathrm{~h}\right)$ by the photoexcitation of fluorenone (Fig. $3 \mathrm{c}$, green dots, red-striped zone). Without photoirradiation, fluorenone itself did not facilitate the ring inversion (Fig. 3c, green dots, before and after red-striped zone). The triplet sensitization should occur smoothly, considering that the $\mathrm{T}_{1}$ state energy of ${ }^{\mathrm{Th} 4}{ }^{\mathbf{C O T}} \mathrm{T}_{\text {Saddle }}$ is supposedly slightly lower than that of fluorenone (Supplementary Discussion). In fact, a photoexcited $\mathrm{T}_{1}$ species of ${ }^{\mathrm{Th}}{ }^{4} \mathrm{COT}_{\text {Saddle }}$ with a lifetime of $2 \mu$ s was observed by TAS upon photoexcitation at $\lambda=420 \mathrm{~nm}$ in the presence of fluorenone (Supplementary Fig. 23). Just in case, when the system was bubbled with oxygen, a possible triplet quencher ${ }^{38}$, ring inversion was no longer facilitated by photoexcitation (Supplementary Fig. 11). These observations strongly support that the photo-accelerated ring inversion of ${ }^{\mathrm{Th}}{ }^{4} \mathbf{C O T}_{\text {Saddle }}$ in the presence of fluorenone originates from its $\mathrm{T}_{1}$ state. As expected, the ring inversion of ${ }^{\text {Th4 }}$ COT $_{\text {Saddle }}$ in the $\mathrm{S}_{1}$ state was unaffected by $\mathrm{O}_{2}$ (Supplementary Fig. 10).

Baird's rule explains why $[4 n]$ annulenes prefer to be planarized in their photoexcited states. As described in Fig. 4a, the ring inversion of ${ }^{\mathrm{Th} 4} \mathrm{COT}_{\text {Saddle }}$ involves its planar transition state. In contrast, ${ }^{\text {Th6 }}{ }^{6} \mathbf{C H}_{\text {Screw }}$ cannot be planarized during its ring inversion process (Fig. $4 \mathrm{~b}$ ). Does photoexcitation affect the ring inversion of ${ }^{\mathrm{Th} 6} \mathrm{CDH}_{\text {Screw }}$ ? Compared with ${ }^{\mathrm{Th} 4} \mathrm{COT}_{\text {Saddle, }}$ ${ }^{\text {Th6 }} \mathrm{CDH}_{\text {Screw }}$ is more prone to thermal ring inversion in the dark, and its enantiomers were racemized in methylcyclohexane, even at $-20^{\circ} \mathrm{C}$ (Fig. $3 \mathrm{~d}$, blue dots, $t_{1 / 2}=18 \mathrm{~h}$ ). Initially, a methylcyclohexane solution of ${ }^{\mathrm{Th}}{ }^{6} \mathrm{CDH}_{\text {Screw }}$ at $-20^{\circ} \mathrm{C}$ was photoexcited at the longest wavelength absorption band $(\lambda=365 \pm 5 \mathrm{~nm})$. However, no acceleration was observed for its ring inversion. TAS of ${ }^{\text {Th6 }} \mathbf{C D H}_{\text {Screw }}$ with photoexcitation at $\lambda=355 \mathrm{~nm}$ indicated the presence of both $\mathrm{S}_{1}$ and $\mathrm{T}_{1}$ states with lifetimes of $70 \mathrm{ps}$ and $350 \mathrm{~ns}$, respectively (Supplementary Figs. 18 and 19). No accelerated ring inversion occurred 
a

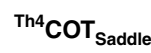

$\theta=13.8^{\circ}$

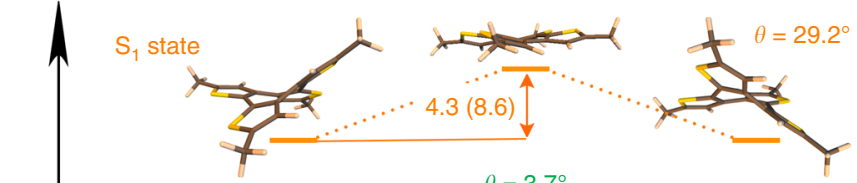

$\theta=3.7^{\circ}$
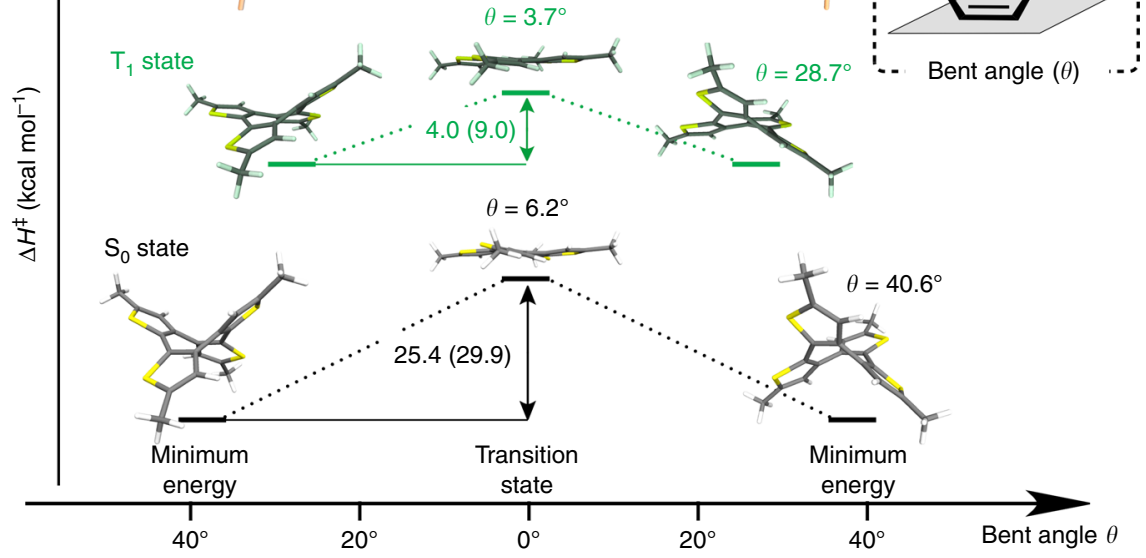

b

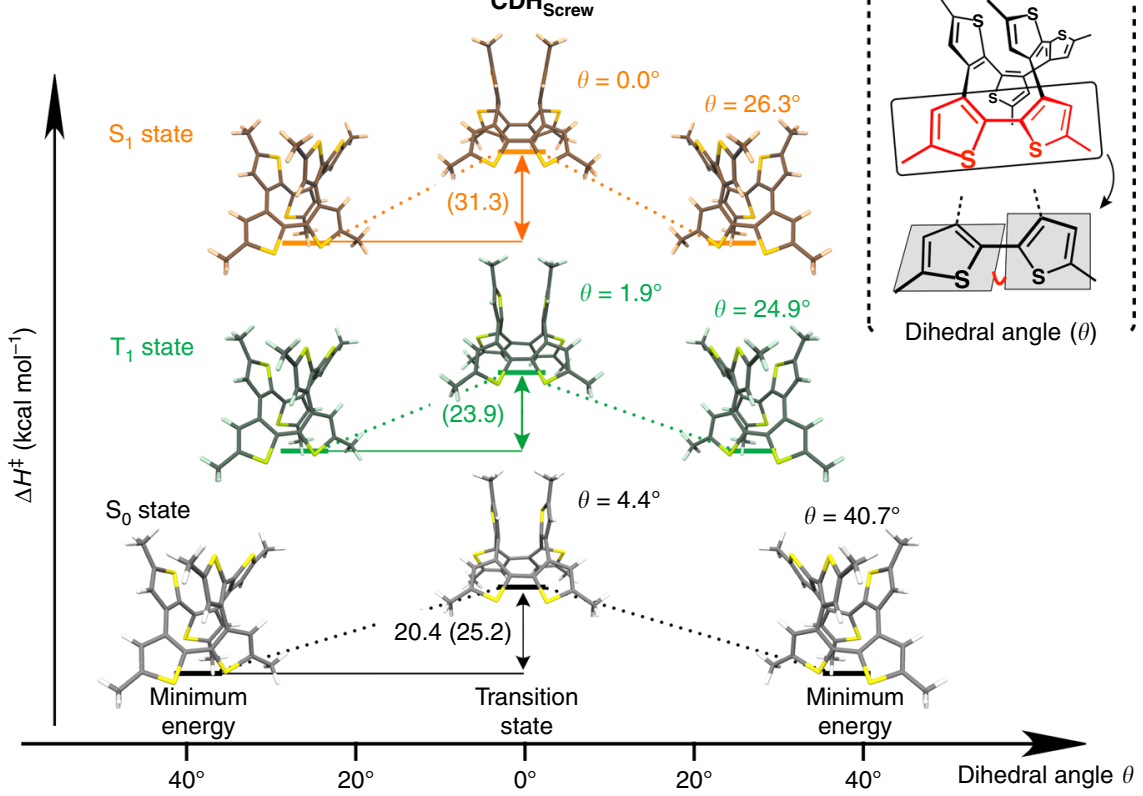

Fig. 4 Ring inversion energetics of ${ }^{\mathbf{T h} 4}{ }^{\mathbf{C O O}} \mathbf{T}_{\text {Saddle }}$ and ${ }^{\mathbf{T h}}{ }^{\mathbf{C}} \mathbf{C D H}_{\text {Screw }}$ a, Conformational change of ${ }^{\text {Th4 }}{ }^{\mathbf{C O}} \mathbf{T}_{\text {Saddle }}$ calculated along the reaction coordinate. b. Conformational change of ${ }^{\mathbf{T}}{ }^{6} \mathbf{C D H}_{\text {screw }}$ calculated along the reaction coordinate. Gray-, green- and orange-colored drawings represent the conformations in the $S_{0}, T_{1}$, and $S_{1}$ states, respectively. For the $S_{0}$ and $T_{1}$ states, the structures were optimized at the B3LYP-D3(BJ)/6-31G(d) level, and the energy values were calculated by single-point calculations at the B3LYP-D3(BJ)/6-311+G(d,p) level using the optimized geometry. For the $S_{1}$ state, the structures were optimized at the TD-B3LYP-D3(BJ)/6-31+G(d,p) level, and the energy values were obtained by the same level of calculation used for the structural optimization. Activation enthalpies experimentally obtained (computationally calculated) are given in $\mathrm{kcal} \mathrm{mol}^{-1}$

when ${ }^{\text {Th6 }}{ }^{\mathrm{CDH}} \mathrm{H}_{\text {Screw }}$ was placed under triplet sensitization conditions using photoexcited fluorenone ( 0.23 equiv.) at $\lambda=420 \pm 5 \mathrm{~nm}$. The contrasting results with planarizable ${ }^{\text {Th4 }}{ }^{\mathbf{C O T}}{ }_{\text {Saddle }}$ and non-planarizable ${ }^{\text {Th6 }}{ }^{\mathbf{C D H}} \mathbf{S c r e w}_{\text {scr }}$ appear reasonable, if the observed phenomena are dominated by Baird's rule. The possible effect of local heating (photothermal activation) on the accelerated ring inversion of ${ }^{\mathrm{Th} 4} \mathbf{C O T}$ Saddle was excluded, as described in the Supplementary Discussion. All these observations indicate that kinetic analysis of the ring inversion events of photoexcited- and ground-state ${ }^{\mathrm{Th} 4}{ }^{\mathrm{COT}} \mathbf{T}_{\text {Saddle, }}$, when compared to those of ${ }^{\text {Th6 }} \mathrm{CDH}_{\text {Screw }}$, enable energetic quantification of Baird aromaticity.
Experimental evaluation of the activation enthalpies of ring inversion. We investigated the ring inversion processes of ${ }^{\text {Th4 }}$ COT $_{\text {Saddle }}$ and ${ }^{\text {Th }}{ }^{6} \mathrm{CDH}_{\text {Screw }}$ at varying temperatures in methylcyclohexane and analyzed their kinetic profiles using the Eyring equation (Supplementary Discussion). Based on the CD spectral decay profiles of ${ }^{\mathbf{T} 4}{ }^{\mathbf{C O}} \mathbf{O T}_{\text {Saddle }}$ at 40,50 , and $60{ }^{\circ} \mathrm{C}$ in the dark, the activation enthalpy of its ring inversion in the ground $\left(\mathrm{S}_{0}\right)$ state was evaluated as $25.4 \mathrm{kcal} \mathrm{mol}^{-1}$ (Supplementary Fig. $13 \mathrm{a}, \mathrm{c})$. The decay profiles of ${ }^{\mathrm{Th} 4} \mathrm{COT}_{\text {Saddle }}$ at 0,10 , and $20{ }^{\circ} \mathrm{C}$ upon photoexcitation afforded activation enthalpies in the $S_{1}$ and $\mathrm{T}_{1}$ states of 4.3 and $4.0 \mathrm{kcal} \mathrm{mol}^{-1}$, respectively (Supplementary Figs. 14 and 15). The calculated activation enthalpies at (TD-) 
a
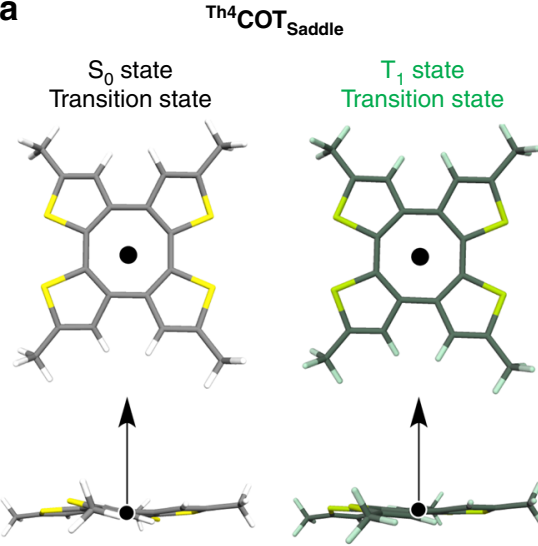

C

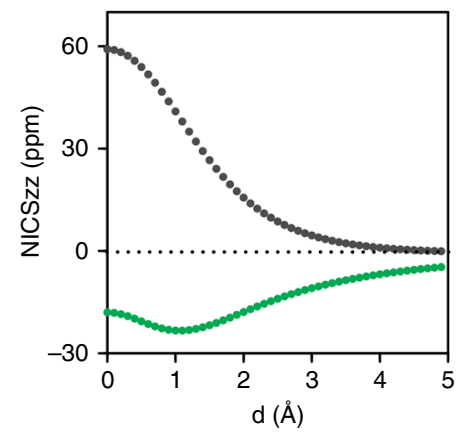

b
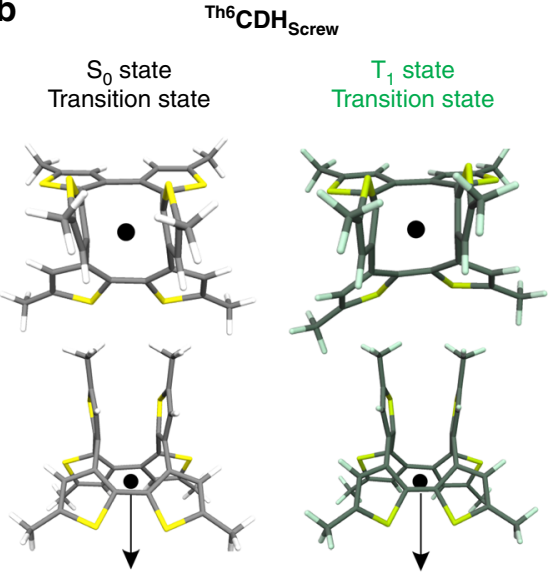

d

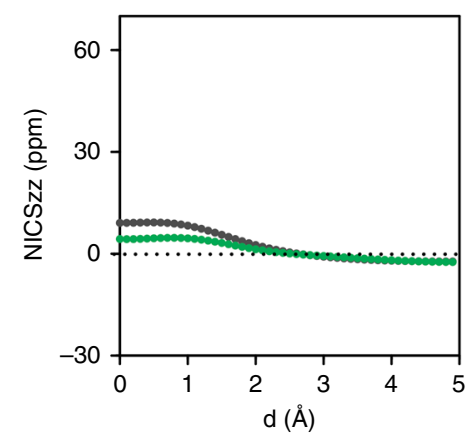

Fig. 5 Nucleus-independent chemical shift (NICS) scans of ${ }^{\text {Th4 }}{ }^{\mathbf{C O}} \mathbf{T}_{\text {Saddle }}$ and ${ }^{\mathbf{T h}} \mathbf{C D D H}_{\mathbf{S c r e w}}$. $\mathbf{a}, \mathbf{b}$, Top and side views of the inversion transition states of ${ }^{\text {Th4 }}{ }^{\mathbf{C O O T}}$ Saddle $(\mathbf{a})$ and ${ }^{\text {Th6 }} \mathbf{C D H}_{\text {Screw }}(\mathbf{b})$ in the $\mathrm{S}_{0}$ and $\mathrm{T}_{1}$ states. $\mathbf{c}, \mathbf{d}, \mathrm{NICS}_{\mathrm{zz}}$ scans of ${ }^{\text {Th4 }}{ }^{\mathbf{C O T}} \mathbf{T}_{\text {Saddle }}(\mathbf{c})$ and ${ }^{\text {Th6 }} \mathbf{C D H}_{\text {Screw }}(\mathbf{d})$, which start from the annulene ring center and scanned along the arrows shown in $\mathbf{a}$ and $\mathbf{b}$. Black- and green-colored dots represent the scans in the $\mathrm{S}_{0}$ and $\mathrm{T}_{1}$ states, respectively

B3LYP-D3(BJ) were 29.9, 8.6, and $9.0 \mathrm{kcal} \mathrm{mol}^{-1}$ for the $\mathrm{S}_{0}, \mathrm{~S}_{1}$, and $\mathrm{T}_{1}$ states, respectively, which are in agreement with the experimental values. It is now clear that the planar transition state in the ring inversion of ${ }^{\text {Th4 }}{ }^{C O T} \mathbf{T}_{\text {Saddle }}$ is photochemically stabilized in the excited $\left(\mathrm{S}_{1} / \mathrm{T}_{1}\right)$ states. In sharp contrast, as described in Fig. $3 \mathrm{~d}$, the inversion rate of ${ }^{\text {Th6 }}{ }^{-} \mathrm{CDH}_{\text {Screw }}$ is unaffected by photoexcitation; thus, the activation enthalpies in the photoexcited $\left(\mathrm{S}_{1} / \mathrm{T}_{1}\right)$ states would not differ from that in the $S_{0}$ state $\left(20.4 \mathrm{kcal} \mathrm{mol}^{-1}\right.$, Supplementary Fig. 13b, d). In other words, no photochemical stabilization occurs at the nonplanar transition state in the ring inversion of ${ }^{\text {Th6 }} \mathbf{C D H}_{\text {Screw. }}$. This is supported by the calculated values at (TD-)B3LYP-D3(BJ) of 25.2, 31.3, and $23.9 \mathrm{kcal} \mathrm{mol}^{-1}$ for the $S_{0}, S_{1}$, and $T_{1}$ states, respectively. The energetic quantification results are consistent with Baird's rule.

Computational investigation of energetics and aromaticity. Quantum chemical calculations are essential to clarify whether our observations, involving photochemical planarization of [ $4 n]$ annulenes, is indeed caused by Baird aromaticity. In [4n] annulenes with fused arene moieties, the excited state structure is in some cases explained by the emergence of Baird aromaticity in the excited $\operatorname{state}^{29}$, but there are also examples where the excited state is located to the arene fragment ${ }^{39}$. Therefore, we performed quantum chemical calculations of the ring inversion processes of ${ }^{\mathrm{Th} 4} \mathrm{COT}_{\text {Saddle }}$ and ${ }^{\mathrm{Th}}{ }^{\mathbf{C}} \mathrm{CDH}_{\text {Screw }}$ in the $\mathrm{S}_{0}, \mathrm{~S}_{1}$, and $\mathrm{T}_{1}$ states. The calculated transition state structures of ${ }^{\text {Th4 }}{ }^{\text {COT }}$ Saddle $_{\text {in the }} S_{0}, S_{1}$, and $T_{1}$ states are quasi-planar, as indicated by the small bent angles $(\theta)$ of the COT core $\left(\theta=6.2,13.8\right.$, and $3.7^{\circ}$ for the $S_{0}, S_{1}$, and $T_{1}$ states, respectively; Fig. 4a). These geometries enable efficient $\mathrm{p}_{\pi^{-}}$orbital overlap, which is in line with observed $8 \pi$-electron conjugation, by means of molecular orbitals and spin densities, in the COT core (Supplementary Figs. 26 and 31). The alternation of $\mathrm{C}-\mathrm{C}$ bond lengths in the COT core at the transition state in the $\mathrm{S}_{0}$ state and equalization of those in the photoexcited $\left(\mathrm{S}_{1} / \mathrm{T}_{1}\right)$ states demonstrate the antiaromatic and aromatic natures of the transition states in the $\mathrm{S}_{0}$ state and photoexcited $\left(\mathrm{S}_{1} / \mathrm{T}_{1}\right)$ states, respectively (Supplementary Fig. 40). Magnetic aromaticity indices ${ }^{40}$, such as anisotropy of the induced current density (ACID) $)^{40-42}$ and nucleus-independent chemical shift (NICS $)^{43-46}$, are commonly utilized to examine tentatively aromatic molecules. For the transition state structures in the $\mathrm{S}_{0}$ and $\mathrm{T}_{1}$ states, paratropic (counterclockwise, antiaromatic) and diatropic (clockwise, aromatic) ring currents, respectively, were observed in the ACID plots (Supplementary Figs. 34 and 36). The NICS $_{z z}$ scans, orthogonal to the central COT ring (Fig. 5a), also showed characteristic positive and negative minima for the transition states in the $\mathrm{S}_{0}$ and $\mathrm{T}_{1}$ states, respectively (Fig. 5c). On the other hand, the magnetic indices of aromaticity for the $S_{1}$ state are harder to assess because ACID is not available and NICS is not well-established (Supplementary Discussion). The $\mathrm{NICS}_{\mathrm{zz}}$ scan, which was obtained with CASSCF(8in8)/ 6-31 + + G(d,p) using Dalton 2016.0 (Supplementary Methods) and should be taken as qualitative rather than quantitative, showed the characteristic aromatic minima at the transition state in the $S_{1}$ state (Supplementary Fig. 39). These tentative findings are consistent with those of Solà and coworkers ${ }^{14}$ who concluded that the corresponding state for the parent COT is highly aromatic according to electronic indices. These calculations indicate that the COT ring of ${ }^{\text {Th4 }}{ }^{\text {COT }}$ Saddle exhibits aromatic nature in the transition state in the $\mathrm{T}_{1}$ state and probably also in the $S_{1}$ state, while in the $S_{0}$ state it is antiaromatic. 
Interestingly, $16 \pi$-electron circuits are formed due to conjugation of the COT core and two adjacent fused thiophene rings in the minimum energy structures of the photoexcited ${ }^{\text {Th4 }}$ COT $_{\text {Saddle }}$. Although the minimum energy structures in the $S_{1}$ and $\mathrm{T}_{1}$ states take a tub-shaped conformation $\left(\theta=29.2^{\circ}\right.$ for $\mathrm{S}_{1}$ and $28.7^{\circ}$ for $\mathrm{T}_{1}$ states; Fig. $4 \mathrm{a}$ ), which is shallower than that in the $\mathrm{S}_{0}$ state $\left(\theta=40.3^{\circ}\right)$, they both have a bond-length equalized COT core. The ACID plot for the minimum energy structure in the $T_{1}$ state showed clear $16 \pi$-electron diatropic ring currents, which comprise the central COT ring and two adjacent thiophene rings (Supplementary Fig. 35). Such $16 \pi$-electron diatropic ring currents were not observed in the minimum energy structure in the $S_{0}$ state (Supplementary Fig. 33). The NICS(1) iso values were also consistent with the formation of a $16 \pi$ conjugation pathway since both the COT ring $(-8.9 \mathrm{ppm})$ and the thiophene rings $(-7.3 /-4.4 \mathrm{ppm}$ above and below the ring, respectively) have negative NICS values. This is in sharp contrast with the NICS (1) iso values in the $S_{0}$ state: $0.0 \mathrm{ppm}$ for COT and $-6.8 /-7.6 \mathrm{ppm}$ (above/below) for the surrounding thiophene rings (Supplementary Table 7). These observations indicate some aromatic character due to $16 \pi$-electron circuits in the minimum energy structure of the photoexcited ${ }^{\text {Th4 }}{ }^{\mathbf{C O O T}} \mathbf{T}_{\text {Saddle. This high- }}$ lights that a careful analysis that considers aromatic circuits from several rings is needed also for polycyclic systems in the excited state, similar as in the ground state ${ }^{47,48}$.

So why is the tub conformation preferred, even in the excited state? Calculations were performed on the model compound ${ }^{\text {Th2 }}$ COT $_{\text {Saddle, where two diagonally placed thiophene rings are }}$ removed to reduce steric repulsions. The optimization demonstrated that ${ }^{\text {Th2 }}{ }^{\text {COT }}$ Saddle in the photoexcited $\left(S_{1} / T_{1}\right)$ states prefers to be planar, which is in sharp contrast with the photoexcited ${ }^{\text {Th4 }}{ }^{4}$ OT $_{\text {Saddle }}$ (Supplementary Fig. 30). In addition, the activation enthalpy for ring inversion in the $S_{0}$ state is lowered to $6.3 \mathrm{kcal} \mathrm{mol}^{-1}$ for ${ }^{\mathrm{Th} 2} \mathrm{COT}_{\text {Saddle }}$ from a calculated value of

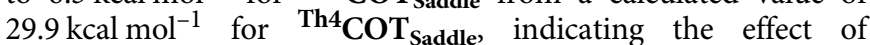
reduced steric strain. According to these model calculations, the shallow tub-shaped minimum energy structures of photoexcited ${ }^{\text {Th4 }}{ }^{C} \mathbf{C T}_{\text {Saddle }}$ represent a balance between maximizing the aromatic conjugation and minimizing the steric strain. Consequently, although a planar structure is favoured if only electronic effects are important, ${ }^{\text {Th4 }}{ }^{\text {COT }}$ Saddle $_{\text {prefers a bent conformation }}$ in the excited state due to steric repulsion between neighboring thiophene rings.

For highly twisted ${ }^{\text {Th6 }}{ }^{\mathrm{CDH}} \mathbf{S}_{\text {Screw }}$, DFT calculations showed multiple dihedral angles of $\sim 90^{\circ}$ in the [12] annulene core, indicating inhibition of full conjugation along the central core at the inversion transition states in the $S_{0}, S_{1}$, and $T_{1}$ states (Fig. $4 b$, Supplementary Fig. 44). This is in line with the observed spin density map at the transition state, showing that triplet excitation is localized to only one part of the annulene core (Supplementary Fig. 32). The $\mathrm{C}-\mathrm{C}$ bond-length profile in the core at the transition states in the $S_{0}, S_{1}$, and $T_{1}$ states exhibits a clear alternating feature (Supplementary Fig. 41). These observations indicate the non-aromatic nature of the [12] annulene core of ${ }^{\mathrm{Th} 6} \mathrm{CDH}_{\text {Screw }}$ in the transition state. Because of the highly strained conformations of ${ }^{\text {Th6 }}{ }^{\mathrm{CDH}_{\text {Screw}}}$, we can only utilize NICS calculations for the transition state structures as a magnetic index of aromaticity. As shown in Fig. $5 \mathrm{~d}$, the near-zero values of the $\mathrm{NICS}_{\mathrm{zz}}$ scans orthogonal to the central rings (Fig. $5 \mathrm{~b}$ ) suggest the non-aromatic nature of ${ }^{\text {Th6 }}{ }^{6} \mathrm{CH}_{\text {Screw. }}$. For the minimum energy structures, a non-aromatic nature is also expected for the $S_{0}$ and $T_{1}$ states because similar bond-length alternation and dihedral angle profiles were observed (Supplementary Figs. 43 and 45). The only exception is the minimum energy structure of the $S_{1}$ state, where bond-length equalization and small dihedral angles were observed, indicating the emergence of aromaticity. This observation is consistent with the higher calculated activation enthalpy for the $S_{1}$ state $\left(31.3 \mathrm{kcal} \mathrm{mol}^{-1}\right)$ compared to the $\mathrm{S}_{0}\left(25.2 \mathrm{kcal} \mathrm{mol}^{-1}\right)$ and $\mathrm{T}_{1}\left(23.0 \mathrm{kcal} \mathrm{mol}^{-1}\right)$ states, which could be attributed to the aromatic stabilization of the $S_{1}$ minimum that is lost at the transition state.

\section{Discussion}

In 1972, Baird theoretically predicted that planar [4n]annulenes, which are energetically unfavorable in the electronic ground state according to Hückel's rule, become favoured upon photoexcitation. Using a particular $[4 n]$ annulene $\left({ }^{\mathrm{T} 4}{ }^{\mathrm{CO}} \mathrm{T}_{\text {Saddle }}\right)$, which undergoes photo-accelerated ring inversion through its planar transition state (Fig. 1c), we succeeded in unambiguous experimental substantiation of Baird's rule from an energetic viewpoint. Additional important support was provided by the lack of photochemical acceleration in the ring inversion of a non-planarizable $[4 n]$ annulene $\left({ }^{\text {Th6 }} \mathbf{C D H}_{\text {Screw }} ;\right.$ Fig. $\left.1 \mathrm{~d}\right)$. The energetic impact of Baird aromaticity $\left(21-22 \mathrm{kcal} \mathrm{mol}^{-1}\right)$, determined by the analysis of the ring inversion kinetics of ${ }^{\text {Th4 }} \mathrm{COT}_{\text {Saddle, }}$ is noteworthy considering the stabilization energy of benzene of $28.8 \mathrm{kcal} \mathrm{mol}^{-1}$, estimated based on experimental heats of formation ${ }^{49}$. Our study will help tailoring the potential energy surfaces of cyclic $\pi$-conjugated hydrocarbons with $4 n \pi$-electrons in their photoexcited states. Such compounds, if planar in the excited states, contribute as a new family of aromatic motifs to the progress of an exciting but much less explored area of organic photochemistry and related materials science.

\section{Methods}

Studies on the ring inversion events of ${ }^{\text {Th4 }}{ }^{\mathrm{COT}}$ Saddle and ${ }^{\text {Th6 }} \mathrm{CDH}_{\text {Screw }}$ ${ }^{\text {Th4 }}{ }^{\mathrm{COT}}$ Saddle was subjected to chiral HPLC using hexane $/ \mathrm{CH}_{2} \mathrm{Cl}_{2}(95 / 5 \mathrm{v} / \mathrm{v})$ as eluent on a chiral DAICEL CHIRALPAK IF column (Supplementary Methods), and two well-separated enantiomer fractions were collected and evaporated to dryness at $25^{\circ} \mathrm{C}$. To the residue from the former or latter fraction was slowly added methylcyclohexane $(3.0 \mathrm{~mL})$, deaerated beforehand by Ar bubbling for $1 \mathrm{~h}$, at $25^{\circ} \mathrm{C}$. The resulting solution was transferred to a quartz cuvette under $\mathrm{Ar}$ at $25^{\circ} \mathrm{C}$ using a cannula to avoid contact with air and was utilized for the kinetic studies of the ring inversion of ${ }^{\mathrm{Th} 4} \mathrm{COT}_{\text {Saddle }}$ at $20^{\circ} \mathrm{C}$. As shown in Fig. 3c, plots of the CD intensity changes at $260 \mathrm{~nm}$ versus time gave the decay profiles in the $\mathrm{S}_{0}$ (blue), $\mathrm{S}_{1}$ (orange; excitation at $365 \mathrm{~nm}$ ), and $\mathrm{T}_{1}$ (green; excitation at $420 \mathrm{~nm}$ with fluorenone) states. ${ }^{\mathrm{T} T h 6} \mathrm{CDH}_{\text {screw }}$ is more subject to thermal ring inversion than ${ }^{\mathrm{Th} 4}{ }^{\mathrm{COT}}$ Saddle. Chiral HPLC separation of its enantiomers was conducted at $0{ }^{\circ} \mathrm{C}$ using hexane/EtOH $(100 / 0.1 \mathrm{v} / \mathrm{v})$ as eluent on a chiral DAICEL CHIRALPAK IA column (Supplementary Methods). To prevent thermal racemization, the collected enantiomer fractions were evaporated at $-40^{\circ} \mathrm{C}$, and the residues were dissolved in chilled methylcyclohexane at $-40^{\circ} \mathrm{C}$. At $-20^{\circ} \mathrm{C}$ under otherwise identical conditions, the resulting solutions were subjected to kinetic studies of the ring inversion of ${ }^{\text {Th6 }} \mathrm{CDH}_{\text {screw }}$ (Fig. 3d), and the CD intensity changes at $280 \mathrm{~nm}$ were plotted versus time. The kinetic analysis was performed according to the method described in the Supplementary Discussion.

Quantum chemical calculations. The molecular geometries in the $\mathrm{S}_{0}$ and $\mathrm{T}_{1}$ states were optimized using B3LYP ${ }^{50}$ augmented by D3(BJ) dispersion ${ }^{51}$ corrections and the $6-31 \mathrm{G}(\mathrm{d})$ basis set using Gaussian 09 Revision E.01 ${ }^{52}$ (for full reference, see Supplementary References). Stationary points, including the minimum energy and transition state structures, were confirmed by frequency calculations. For the transition state structures, IRC analysis was further carried out. Single-point electronic energies were calculated using the $6-311+G(d, p)$ basis set and used together with the corrections to the enthalpy taken from B3LYP-D3(BJ)/6-31G(d). For the $S_{1}$ state, we used TD-B3LYP/6-31+G(d,p) and both Gaussian 09 Revision E. $01^{52}$ and Gaussian 16 Revision A. $03^{53}$ (for full reference, see Supplementary References). The use of TD-DFT for the $S_{1}$ surface was validated for ${ }^{\text {Th4 }}{ }^{\text {COT }} T_{\text {Saddle }}$ by comparison with ab initio methods (Supplementary Methods). NICS scans were calculated with GIAO-B3LYP/6-311+G(d,p) using the Aroma 1.0 package $^{43}$ (for full reference, see Supplementary References). ACID plots were calculated with CSGT-B3LYP/6-311+G(d,p).

Data availability. All relevant data are included in full within this paper and in the Supplementary Information. 
Received: 21 February 2017 Accepted: 20 June 2017

Published online: 24 August 2017

\section{References}

1. Spitler, E. L., Johnson, C. A. II \& Haley, M. M. Renaissance of annulene chemistry. Chem. Rev. 106, 5344-5386 (2006).

2. Gleiter, R., Haberhauer, G. \& Hoffmann, R. Aromaticity And Other Conjugation Effects (Wiley-VCH, 2012).

3. Hückel, E. Quantentheoretische beiträge zum benzolproblem. I. Die elektronenkonfiguration des benzols und verwandter verbindungen. Z. Physik 70, 204-286 (1931).

4. Paquette, L. A. The renaissance in cyclooctatetraene chemistry. Tetrahedron 31, 2855-2883 (1975).

5. Klärner, F.-G. About the antiaromaticity of planar cyclooctatetraene. Angew. Chem. Int. Ed. 40, 3977-3981 (2001).

6. Slayden, S. W. \& Liebman, J. F. The energetics of aromatic hydrocarbons: an experimental thermochemical perspective. Chem. Rev. 101, 1541-1566 (2001).

7. Nishinaga, T., Ohmae, T. \& Iyoda, M. Recent studies on the aromaticity and antiaromaticity of planar cyclooctatetraene. Symmetry 2, 76-97 (2010).

8. Wu, J. I., Fernández, I., Mo, Y. \& Schleyer, P. v. R. Why cyclooctatetraene is highly stabilized: the importance of "two-way" (double) hyperconjugation. J. Chem. Theory Comput. 8, 1280-1287 (2012).

9. Baird, N. C. Quantum organic photochemistry. II. Resonance and aromaticity in the lowest $3 \pi \pi^{\star}$ state of cyclic hydrocarbons. J. Am. Chem. Soc 94, 4941-4948 (1972).

10. Aihara, J. Aromaticity-based theory of pericyclic reactions. Bull. Chem. Soc. Jpn 51, 1788-1792 (1978)

11. Ottosson, H. Exciting excited-state aromaticity. Nat. Chem. 4, 969-971 (2012).

12. Karadakov, P. B. Ground- and excited-state aromaticity and antiaromaticity in benzene and cyclobutadiene. J. Phys. Chem. A 112, 7303-7309 (2008)

13. Karadakov, P. B. Aromaticity and antiaromaticity in the low-lying electronic states of cyclooctatetraene. J. Phys. Chem. A 112, 12707-12713 (2008).

14. Feixas, F., Vandenbussche, J., Bultinck, P., Matito, E. \& Solà, M. Electron delocalization and aromaticity in low-lying excited states of archetypal organic compounds. Phys. Chem. Chem. Phys. 13, 20690-20703 (2011).

15. Rosenberg, M., Dahlstrand, C., Kilså, K. \& Ottosson, H. Excited state aromaticity and antiaromaticity: opportunities for photophysical and photochemical rationalizations. Chem. Rev. 114, 5379-5425 (2014).

16. Papadakis, R. \& Ottosson, H. The excited state antiaromatic benzene ring: a molecular Mr Hyde? Chem. Soc. Rev. 44, 6472-6493 (2015).

17. Wan, P. \& Krogh, E. Evidence for the generation of aromatic cationic systems in the excited state. Photochemical solvolysis of fluoren-9-ol. J. Chem. Soc. Chem. Commun. 1985, 1207-1208 (1985).

18. McAuley, I., Krogh, E. \& Wan, P. Carbanion intermediates in the photodecarboxylation of benzannelated acetic acids in aqueous solution. J. Am. Chem. Soc. 110, 600-602 (1988).

19. Wan, P., Krogh, E. \& Chak, B. Enhanced formation of $8 \pi(4 n)$ conjugated cyclic carbanions in the excited state: first example of photochemical C-H bond heterolysis in photoexcited suberene. J. Am. Chem. Soc. 110, 4073-4074 (1988).

20. Krogh, E. \& Wan, P. Photodecarboxylation of diarylacetic acids in aqueous solution: enhanced photogeneration of cyclically conjugated eight $\pi$ electron carbanions. J. Am. Chem. Soc. 114, 705-712 (1992).

21. Ottosson, H. et al. Scope and limitations of Baird's theory on triplet state aromaticity: application to the tuning of singlet-triplet energy gaps in fulvenes. Chem. Eur. J 13, 6998-7005 (2007).

22. Rosenberg, M., Ottosson, H. \& Kilså, K. Influence of excited state aromaticity in the lowest excited singlet states of fulvene derivatives. Phys. Chem. Chem. Phys. 13, 12912-12919 (2011).

23. Möllerstedt, H., Piqueras, M. C., Crespo, R. \& Ottosson, H. Fulvenes, fulvalenes, and azulene: are they aromatic chameleons? J. Am. Chem. Soc. 126, 13938-13939 (2004)

24. Mohamed, R. K. et al. The missing $\mathrm{C}_{1}-\mathrm{C}_{5}$ cycloaromatization reaction: triplet state antiaromaticity relief and self-terminating photorelease of formaldehyde for synthesis of fulvenes from enynes. J. Am. Chem. Soc. 137, 15441-15450 (2015).

25. Papadakis, R. et al. Metal-free photochemical silylations and transfer hydrogenations of benzenoid hydrocarbons and graphene. Nat. Commun. 7, 12962 (2016).

26. Sung, Y. M. et al. Reversal of Hückel (anti)aromaticity in the lowest triplet states of hexaphyrins and spectroscopic evidence for Baird's rule. Nat. Chem. 7, 418-422 (2015).
27. Sung, Y. M. et al. Switching between aromatic and antiaromatic 1,3-phenylenestrapped [26]- and [28] hexaphyrins upon passage to the singlet excited state. J. Am. Chem. Soc. 137, 11856-11859 (2015).

28. Oh, J. et al. Aromaticity reversal in the lowest excited triplet state of archetypical Möbius heteroannulenic systems. Angew. Chem. Int. Ed. 55, 6487-6491 (2016).

29. Shukla, D. \& Wan, P. Evidence for a planar cyclically conjugated $8 \pi$ system in the excited state: large stokes shift observed for dibenz $[b, f]$ oxepin fluorescence. J. Am. Chem. Soc. 115, 2990-2991 (1993).

30. Yuan, C. et al. A $\pi$-conjugated system with flexibility and rigidity that shows environment-dependent RGB luminescence. J. Am. Chem. Soc. 135, 8842-8845 (2013).

31. Garavelli, M. et al. Cyclooctatetraene computational photo- and thermal chemistry: a reactivity model for conjugated hydrocarbons. J. Am. Chem. Soc. 124, 13770-13789 (2002).

32. Marsella, M. J., Reid, R. J., Estassi, S. \& Wang, L.-S. Tetra[2,3-thienylene]: a building block for single-molecule electromechanical actuators. J. Am. Chem. Soc. 124, 12507-12510 (2002).

33. Wang, Y. et al. Efficient synthesis of trimethylsilyl-substituted dithieno[2,3$\left.b: 3^{\prime}, 2^{\prime}-d\right]$ thiophene, tetra[2,3-thienylene] and hexa[2,3-thienylene] from substituted [3,3']bithiophenyl. Synlett 15, 2390-2394 (2007).

34. Fratev, F., Monev, V. \& Janoschek, R. Ab initio study of cyclobutadiene in excited states: optimized geometries, electronic transitions and aromaticities. Tetrahedron 38, 2929-2932 (1982).

35. Gogonea, V., Schleyer, PvonR. \& Schreiner, P. R. Consequences of triplet aromaticity in $4 n \pi$-electron annulenes: calculation of magnetic shieldings for open-shell species. Angew. Chem. Int. Ed. 37, 1945-1948 (1998).

36. Zilberg, S. \& Haas, Y. Two-state model of antiaromaticity: the triplet state. Is Hund's rule violated? J. Phys. Chem. A 102, 10851-10859 (1998).

37. Andrews, L. J., Deroulede, A. \& Linschitz, H. Photophysical processes in fluorenone. J. Phys. Chem. 82, 2304-2309 (1978).

38. Kearns, D. R. Physical and chemical properties of singlet molecular oxygen. Chem. Rev. 71, 395-427 (1971).

39. Yuan, C. et al. Hybridization of a flexible cyclooctatetraene core and rigid aceneimide wings for multiluminescent flapping $\pi$ systems. Chem. Eur. J 20, 2193-2200 (2014).

40. Gershoni-Poranne, R. \& Stanger, A. Magnetic criteria of aromaticity. Chem Soc. Rev. 44, 6597-6615 (2015).

41. Herges, R. \& Geuenich, D. Delocalization of electrons in molecules. J. Phys Chem. A 105, 3214-3220 (2001).

42. Geuenich, D., Hess, K., Köhler, F. \& Herges, R. Anisotropy of the induced current density (ACID), a general method to quantify and visualize electronic delocalization. Chem. Rev. 105, 3758-3772 (2005).

43. Rahalkar, A. \& Stanger, A. “Aroma” http://chemistry.technion.ac.il/members/ amnon-stanger/

44. Stanger, A. Nucleus-independent chemical shifts (NICS): distance dependence and revised criteria for aromaticity and antiaromaticity. J. Org. Chem. 71, 883-893 (2006).

45. Jiménez-Halla, J. O. C., Matito, E., Robles, J. \& Solà, M. Nucleus-independent chemical shift (NICS) profiles in a series of monocyclic planar inorganic compounds. J. Organomet. Chem. 691, 4359-4366 (2006).

46. Chen, Z., Wannere, C. S., Corminboeuf, C., Puchta, R. \& Schleyer, P. v. R. Nucleus-independent chemical shifts (NICS) as an aromaticity criterion. Chem. Rev. 105, 3842-3888 (2005).

47. Fias, S., Fowler, P. W., Delgado, J. L., Hahn, U. \& Bultinck, P. Correlation of delocalization indices and current-density maps in polycyclic aromatic hydrocarbons. Chem. Eur. J. 14, 3093-3099 (2008).

48. Aihara, J. Magnetic resonance energy and topological resonance energy. Phys. Chem. Chem. Phys. 18, 11847-11857 (2016).

49. Mo, Y. \& Schleyer, P. v. R. An energetic measure of aromaticity and antiaromaticity based on the Pauling-Wheland resonance energies. Chem. Eur. J 12, 2009-2020 (2006).

50. Stephens, P. J., Devlin, F. J., Chabalowski, C. F. \& Frisch, M. J. Ab initio calculation of vibrational absorption and circular dichroism spectra using density functional force fields. J. Phys. Chem. 98, 11623-11627 (1994).

51. Grimme, S., Ehrlich, S. \& Goerigk, L. Effect of the damping function in dispersion corrected density functional theory. J. Comput. Chem. 32, 1456-1465 (2011).

52. Frisch, M. J. et al. Gaussian 09, Revision E.01 (Gaussian, Inc., Wallingford CT, 2009).

53. Frisch, M. J. et al. Gaussian 16, Revision A.03 (Gaussian, Inc., Wallingford CT, 2016).

\section{Acknowledgements}

We thank Prof. Jun-ichi Aihara from Department of Chemistry, Shizuoka University for valuable discussions. We also thank Prof. Masahiro Yamanaka from Department of Chemistry, Rikkyo University for valuable discussions. K.J. and H.O. thank Prof. R. Herges for providing the AICD 2.0.0 program. This work was financially supported by a Grant-in-Aid for Specially Promoted Research (25000005) on "Physically Perturbed 
Assembly for Tailoring High-Performance Soft Materials with Controlled Macroscopic Structural Anisotropy” for T.A. and Y.I.; M.U. thanks JSPS for a Young Scientist Fellowship and the Program for Leading Graduate Schools (MERIT). The work at Yonsei University was supported by Samsung Science and Technology Foundation under Project Number SSTF-BA1402-10. H.O. and K.J. acknowledge the Swedish Research Council (project grant 2015-04538) for support. Financial supports by Grant-in-Aids for Scientific Research, Challenging Exploratory Research, Promotion of Joint International Research (Fostering Joint International Research), and on Innovative Areas "Photosynergetics" (Grant Numbers JP15H03779, JP15K13642, JP16KK0111, and JP17H05261) from JSPS for T.M. is greatly acknowledged. Part of this work was conducted at the Advanced Characterization Nanotechnology Platform of the University of Tokyo, supported by the Ministry of Education, Culture, Sports, Science and Technology (MEXT), Japan. The Swedish National Infrastructure for Computation (SNIC) through NSC, Linköping, and HPC2N, Umeå, is acknowledged for computer time. A portion of the computations was performed using Research Center for Computational Science, Okazaki, Japan.

\section{Author contributions}

M.U., T.A., and Y.I. initiated the work on the ring inversion kinetics of thiophene-fused annulenes. K.J. and H.O. proposed the incorporation of Baird aromaticity. M.U. and Y.I. performed the experiments and analyzed the data. K.J. performed the calculations, and, together with H.O., analyzed the data. Y.M.S. performed the transient absorption spectroscopies, and, together with D.K., analyzed the data. T.M. provided the theoretical basis for analyzing the $\mathrm{CD}$ intensity decay profiles to obtain the energetics of the system. M.U., K.J., H.O., T.A., and Y.I. wrote the paper. All authors discussed the results and commented on the manuscript.

\section{Additional information}

Supplementary Information accompanies this paper at doi:10.1038/s41467-017-00382-1.

Competing interests: The authors declare no competing financial interests.

Reprints and permission information is available online at http://npg.nature.com/ reprintsandpermissions/

Publisher's note: Springer Nature remains neutral with regard to jurisdictional claims in published maps and institutional affiliations.

Open Access This article is licensed under a Creative Commons Attribution 4.0 International License, which permits use, sharing, adaptation, distribution and reproduction in any medium or format, as long as you give appropriate credit to the original author(s) and the source, provide a link to the Creative Commons license, and indicate if changes were made. The images or other third party material in this article are included in the article's Creative Commons license, unless indicated otherwise in a credit line to the material. If material is not included in the article's Creative Commons license and your intended use is not permitted by statutory regulation or exceeds the permitted use, you will need to obtain permission directly from the copyright holder. To view a copy of this license, visit http://creativecommons.org/ licenses/by/4.0/.

(C) The Author(s) 2017 